\title{
Family Physicians' Experiences of Physical Examination
}

Martina Ann Kelly, MA, MBBCb, FRCGP, CCFP ${ }^{1}$

Lisa Katbryn Freeman, BSc (Hon), $M D, C C F P, M P H, F R C P C^{2}$

Tim Dornan, MA, DM, FRCP, MHPE, $P b D^{3}$

'Department of Family Medicine, Cumming School of Medicine, University of Calgary, Alberta, Canada

${ }^{2}$ Department of Family Medicine, Faculty of Medicine \& Dentistry, University of Alberta, Alberta, Canada

${ }^{3}$ Centre for Medical Education, Queen's University Belfast, Belfast, Northern Ireland, United Kingdom

Conflicts of interest: authors report none.

\section{CORRESPONDING AUTHOR}

Martina Kelly, MA, MBBCh, FRCGP, CCFP Department of Family Medicine Cumming School of Medicine University of Calgary, Health Sciences Centre

3330 Hospital Drive NW

Calgary T2N 4N1, Alberta, Canada

makelly@ucalgary.ca

\begin{abstract}
PURPOSE The increased availability of reliable diagnostic technologies has stimulated debate about the utility of physical examination in contemporary clinical practice. To reappraise its utility, we explored family physicians' experiences.
\end{abstract}

METHODS Guided by principles of phenomenology, we conducted in-depth qualitative interviews exploring 16 family physicians' experiences of conducting physical examination: 7 (44\%) men and 9 women (56\%) whose clinical experience varied widely, from $11(69 \%)$ urban and $5(31 \%)$ rural locations. We recorded the interviews, transcribed them verbatim, and identified initial themes using template analysis. We worked reflexively, critiquing our own and other team members' interpretations, in order to synthesize and write a final interpretation.

RESULTS Participants described 2 facets of physical examination: making diagnoses and estimating prognoses rationally and objectively; and responding subjectively and intuitively to patients' illnesses, which formed relationships between doctor and patient that enacted medical care in the moment. Physical examination allowed physicians to use their own bodies to experience patients' illnesses. Performing physical examination was integral to being a family doctor because it promoted rapport and developed trust.

CONCLUSIONS Physical examination is part of the identity of family physicians. It not only contributes diagnostic information but is a therapeutic intervention in and of itself. Physical examination contributes to relationship-centered care in family practice.

Ann Fam Med 2019;17:304-310. https://doi.org/10.1370/afm.2420.

\section{INTRODUCTION}

$\mathrm{T}$

he role of physical examination in contemporary medicine is debated ${ }^{1-4}$ because clinical skills, like other aspects of practice, are being scrutinized for supporting evidence. Critics draw attention to the low diagnostic accuracy of physical examination ${ }^{4}$ and ask whether it is an outdated practice. As technology has gained ground and graduates have questioned the utility of physical examination, ${ }^{5}$ they have become progressively less confident about performing it..$^{6,7}$ Meanwhile, proponents argue that graduates' declining physical examination skills are increasing health care costs by making misdiagnosis more likely. ${ }^{8-10}$ This impasse calls for a deeper examination of how physical examination can contribute to family practice.

The debate about whether physical examination should be taught and how it can contribute to practice has taken place in the rational and objective territory of clinical decision making..$^{11-13}$ Here, physicians are neutral interrogators of patients' passive bodies. But physicians also practice subjectively. Advocates for physical examination argue that it is a cornerstone of medicine, a privileged human interaction ${ }^{14}$ within an age-old tradition of laying on hands. It is a symbolic enactment of healing, which expresses the fundamental humanity of doctor-patient relationships. ${ }^{15}$ In support of this perspective, the experiences of both patients ${ }^{16,17}$ and physicians ${ }^{18}$ suggest that physical examination serves a healing purpose as well as a diagnostic one. These narratives describe how the subtle exchange of a glance or an unexpected tactile sensation led to a revelatory insight that formed a 
bond between a patient and a physician. According to these accounts, physical interactions are entry points to existential engagements between patients and physicians. Research into physicians' subjective experiences is fragmentary and limited, however. ${ }^{19,20}$

We reasoned that the debate about physical examination would be more balanced if we articulated valid, subjective reasons for performing it. This led to the research question: "What are family physicians' experiences of performing physical examination?"

\section{METHODS}

\section{Setting}

This study was conducted in family practices in Alberta, Canada in 2016.

\section{Theoretical Approach}

This qualitative study focused on family physicians' experience of physical examination by using a phenomenological approach. The starting point of this approach is to consider a phenomenon, in this case physical examination, and question what features make the phenomenon what it is. This study, which drew on ideas from 2 different philosophers, MerleauPonty and Van Manen, obtained family physicians' detailed descriptions of their everyday experiences of physical examination.

\section{Sampling and Recruitment}

Sampling and analysis were iterative. We first sent an introductory e-mail outlining the study to family physicians on family medicine faculty lists (University of Calgary) and known to us. All potential participants who e-mailed expressions of interest to M.A.K. or L.K.F. agreed to be interviewed, providing us with a convenience sample. As the study progressed, we wondered whether rural physicians having less access to diagnostic testing and more embedded relationships with patients would have different experiences. We therefore switched to snowball sampling, identifying potential interviewees from participants' recommendations. This sampling strategy was appropriate because sampling in phenomenological research is guided by participants' ability to illuminate the phenomenon. Although sampling can never be "complete," ${ }^{21}$ we judged recruitment to be sufficient when a wide range of participants had described a rich set of informative experiences.

\section{Data Collection}

M.A.K. or L.K.F. conducted individual interviews in person (14 participants) or by telephone (2 remote rural participants) in order to gather as much descrip- tive detail of individuals' experiences as possible. We conducted interviews at locations convenient to participants, such as their clinics, university offices, or coffee shops. We opened interviews by asking participants to select an actual experience of physical examination that they could recall in detail. We prompted participants to give rich details of the experience, ${ }^{22}$ including where the examination took place, who was in the room, and how they had used the space in the examination room (see Supplemental Appendix, http:// www.AnnFamMed.org/content/17/4/304/suppl/DC1 for interview guide). We audio recorded interviews (34 to 90 minutes) for verbatim transcription.

\section{Analysis}

Our research team comprised a family physician with 20 years in practice (M.A.K.), a recent family medicine graduate and public health physician (L.K.F.), and a retired internist (T.D.). A specific feature of phenomenological research is the requirement for researchers to pay attention to their own preconceptions about the topic of interest. They examine how their assumptions, attitudes, and understandings of the topic, including the influences of gender, ethnicity, and prior experiences, influence their interpretations. ${ }^{21}$ M.A.K. started the study because she noted that residents questioned the value of physical examination, sometimes prioritizing its predictive value over patients' requests for reassurance. This contrasted with her personal practice, in which she often performed physical examination, even if she though its diagnostic yield was low. L.K.F., a recent graduate, was interested in understanding why physicians performed exams, because she did them without much critical thought and saw them as integral to practice but was hearing more and more how others were not performing physical examinations. T.D. participated in the study because his experiences of providing secondary and tertiary care showed how technically proficient medicine improved health outcomes when it was provided within intersubjective relationships with patients.

We started the study by interviewing each other about our interest in the research question, examining whether our perceptions were influenced by our different amounts of clinical practice, training in different countries (Ireland, the United Kingdom, and Canada) with differing models of health care delivery, and having different access to diagnostics. We probed each other's interpretations as the study progressed, moving back and forth between transcripts and our analysis. This process was facilitated by individual coding of transcripts followed by group discussions (in person and via Skype), in which we questioned each other's interpretations. 


\begin{tabular}{|c|c|c|c|}
\hline Theme & Explanation 22,36 & Subtheme & Code \\
\hline \multirow{4}{*}{$\begin{array}{l}\text { Gnostic } \\
\text { experience }\end{array}$} & \multirow{4}{*}{$\begin{array}{l}\text { From the Greek gnos- } \\
\text { tikos, meaning "one } \\
\text { who knows," as related } \\
\text { to the mind, reason, } \\
\text { and judgment. }\end{array}$} & \multirow{2}{*}{$\begin{array}{l}\text { Doctor as } \\
\text { detective }\end{array}$} & Following clues \\
\hline & & & Planning next steps \\
\hline & & \multirow{2}{*}{$\begin{array}{l}\text { Being } \\
\text { thorough }\end{array}$} & Old-school doctor \\
\hline & & & What if? \\
\hline \multirow{10}{*}{$\begin{array}{l}\text { Pathic } \\
\text { experience }\end{array}$} & \multirow{10}{*}{$\begin{array}{l}\text { From pathos, meaning } \\
\text { "suffering or passion." } \\
\text { Relates to personal } \\
\text { presence, relational } \\
\text { perceptiveness, emo- } \\
\text { tional awareness, and } \\
\text { embodied experience } \\
\text { of the senses. }\end{array}$} & \multirow{3}{*}{$\begin{array}{l}\text { Relational } \\
\text { experience }\end{array}$} & Expected by patients \\
\hline & & & Reassured patients \\
\hline & & & Contributed to the relationship \\
\hline & & \multirow{3}{*}{$\begin{array}{l}\text { Actional } \\
\text { experience }\end{array}$} & Doing \\
\hline & & & Routines and personal style \\
\hline & & & Laying on of hands \\
\hline & & $\begin{array}{l}\text { Temporal } \\
\text { experience }\end{array}$ & Slowing of time \\
\hline & & \multirow{3}{*}{$\begin{array}{l}\text { Corporeal } \\
\text { experience }\end{array}$} & Physical reactions \\
\hline & & & Never leave you \\
\hline & & & Knowing normal \\
\hline
\end{tabular}

The Conjoint Health Research Ethics Board, University of Calgary and Health Research Ethics BoardHealth Panel at the University of Alberta approved the project.

\section{FINDINGS}

Sixteen family physicians participated. Nine participants were women, and 11 worked in urban practice (Table 2). They described a wide range of experiences, such as periodic health examinations, examinations for acute illness (sore throat, acute abdomen, fractures), and finding both the normal and the abnormal or unexpected.

Two Greek words (gnostic and

We analyzed the data by using a template method. ${ }^{23-25}$ As in thematic content analysis, we first read and reread transcripts to familiarize ourselves with the data. We then open-coded 3 interviews, grouping together relevant excerpts (tagged by interview number and line number) and developing a hierarchy of codes (see Supplemental Appendix for an early template). We then applied the newly formed template to more interviews, revising it to incorporate new codes or themes as presented by the data, reorganizing it until we agreed on a final set of codes and themes (Table 1). The resulting template provided a tool to help us reflexively question the data rather than a fixed and final interpretation. ${ }^{26}$ To increase our confidence in the template, we reexamined the data, looking for differences between early, midcareer, and more experienced physicians, gender, and different work settings.

As advised by van Manen, we informed our interpretation by reading a range of phenomenological texts $^{27-33}$ and academic health care literature, ${ }^{34,35}$ asking, "How has this topic been addressed elsewhere?" and, "How can these ideas inform our understanding?" We presented preliminary findings at family medicine conferences, using audience members' responses as a way of evaluating provisional interpretations. patbic), used by phenomenologists to distinguish contrasting facets of human experience, ${ }^{22,36}$ summarize the main findings. These words are more familiar to physicians than they may first appear. The objective and rational facet of physical examination served gnostic purposes: diagnostic and prognostic. But that was not physical examination's only purpose. Its pathic facet served tacit, deeply subjective purposes in doctors' relationships with patients; physical examination could also be empathic. The words gnostic and patbic are so deeply embedded in medical language $e^{37}$ and philosophy, and so clearly describe 2 complementary facets of practice, that we use them despite their relative unfamiliarity. We first present evidence to support the distinction between gnostic and pathic experience and then describe 4 subtypes of pathic experience: experiencing through relationship, experiencing through doing, experiencing through time, and experiencing through the body.

Physical examination was an embodied part of participants' practice, part of being a physician.

A doctor who did not examine patients was not a "good doctor," "because that's about connection and relationship and if you don't have that, I don't care how good a doctor you are, you are not a good doctor. ... [It's] specific to being a

\section{Presentation of Findings}

We have shortened phrases such as "participants experienced physical examination as intellectual and rational" to "physical examination was intellectual and rational" to make the article more readable; however, we ask readers to interpret such statements as interpretations of human experience, not as truth claims.

\section{Table 2. Description of Participants}

\begin{tabular}{lcccccc}
\hline $\begin{array}{l}\text { Years in } \\
\text { Practice }\end{array}$ & N (\%) & Male & Female & Urban & Rural & $\begin{array}{c}\text { Teaching } \\
\text { Practice }\end{array}$ \\
\hline$<5$ years & $4(25)$ & 3 & 1 & 3 & 1 & 0 \\
6-19 years & $4(25)$ & 0 & 4 & 2 & 2 & 2 \\
$>20$ years & $8(50)$ & 4 & 4 & 6 & 2 & 5 \\
Total & $16(100)$ & 7 & 9 & 11 & 5 & 7 \\
\hline
\end{tabular}


physician. So that part is special. That's mine." (participant 9, female, urban practice, $>20$ years' experience)

\section{Physical Examination as Gnostic}

Physical examination was intellectual and rational. It confirmed or refuted working hypotheses generated by the history. "I use physical exam to confirm what I'm looking for in the history, rule out what I'm looking to rule out. Rarely is there an absolute surprise but I don't want to miss it" (participant 2, female, urban practice, $>20$ years' experience). It helped participants rise to the intellectual challenge of physical diagnosis. "I felt like I had a clue and I wanted to pursue it" (participant 4, male, urban academic practice, $>20$ years' experience). "Old-school" or "old-fashioned" physical examination had to be thorough, so as not to "miss something." Occasional experiences of finding the unexpected reinforced participants' habit of examining patients: "I find something completely new or unrelated that I might not have seen, you know, there's a reason we call them incidentalomas, so I think it's always worth doing that exam" (participant 3, male, locum, urban practice, $<5$ years' experience). Although history taking was fundamental to making diagnoses, consultations that included physical examination felt more complete.

\section{Physical Examination as Pathic}

Physical examination also had a subtle facet, whose essence was in the subjective and social interaction between patient and doctor. Physical examination was integral to participants' relationships with patients: even when it was not "clinically necessary," the doctor or patient might expect it. Fulfilling the expectation built the relationship between them.

I think you do make a connection . . . between 2 people [so] that pretty well no amount of talking even with the best communication skills quite equals what that means to people, so yeah, I think it is a huge part of it for both sides. If you didn't do that, then you're a technician, ... we're not a physician anymore. We're healers, ... and part of that is making a connection and an ultrasound machine is not a connection. (participant 14, female, urban practice, $>20$ years' experience)

Performing physical examination was important because "going through the motions" reassured patients and fulfilled participants' role as physicians. A rural physician describes how you can learn physical examination only by doing it, eventually reaching a point where the physician's body knows exactly what to do. "You can talk about it, you can talk about the theory behind it, ... but you have to do it" (participant 8 , male, rural practice, $>20$ years' experience). Participants honed their styles over time. They took a "top to toe" approach, explaining what they were doing as they were going or making "small talk." They examined patients "almost without thinking." "Half the time they're so healthy, you might be . . . not totally focusing and maybe going through the motions because it's automatic at this stage" (participant 13, female, rural practice, 6-19 years' experience). Laying on hands somehow relayed information that participants had not registered intellectually. "The routine performance that reveals something more, there is a process about laying on of hands" (participant 12, male, retired, urban practice, $>20$ years' experience).

Physical examination also had a temporal dimension. From something that "only takes a moment" when normal, the experience of time and "being in the moment" came to the fore when physical examination revealed the unexpected, such as a mass. Here, a family doctor describes being unable to hear the heartbeat of a fetus.

How you manage that couple of minutes where you go searching. Is it my technique? Am I just missing it? Is the machine not going well, or do we really have a problem here? Trying to manage that 20 to probably 60 seconds of just awful anxiety without really deciding how much you're relaying to the patient during that timeframe. . . There's just numerous things there ... we're generally ... unaware of ... that suddenly become of absolute ultimate importance. (participant 14 , female, urban practice, $>20$ years' experience)

Physical examination was associated with physical reactions, experienced through the physician's body, as exemplified by the quotes above and below.

You walk into a room, and you look at a kid and you go oops, and your stomach knots- that child is sick. All you have done is look at them, but you know that baby is not well. You get that urgent feeling in your body, telling yourself to breathe, tell me your story, breathe, give me that baby. I want to look at that baby. (participant 9, female, urban practice, $>20$ years' experience)

Experiences of discovering something abnormal "just never leave you," "they are stuck in [your] mind" (participant 12, male). Repeated practice enabled participants to "know normal" in a physically embodied way. "It's that Gestalt feeling of this just doesn't feel the same, right, you know, the abdomen that feels a bit doughy or um, you know, it just feels different" (participant 1 , female, urban practice, $>20$ years' experience).

\section{DISCUSSION}

Participants experienced physical examination as an integral part of being a good doctor. It helped them rule physical diagnoses in or out and yielded 
unexpected findings. Diagnosis and prognosis were only 2 functions of physical examination, however. It also had subjective functions that were inextricably linked to its objective functions. Physical examination enacted physicians' identities in fluent but individual ways. It built empathic relationships between them and patients. Depending on its content and context, physical examination made time stand still or rush by. The embodied experience of physical examination was a means of knowing the normal and being surprised by the abnormal, a means of experiencing and remembering.

Our study has limitations. We do not know what patients experienced or what they expected. However, previous studies indicate that patients expect to be examined and are less satisfied when physicians do not examine them. ${ }^{38,39}$ We did not directly observe participants' physical examinations and relied on their self-reports, sometimes long after the events they described. A key feature of this type of work, its interpretive nature, limits its generalizability. Our sample is small, and other physicians may not necessarily share these experiences in a similar manner. Our participants self-selected into this research, and it is possible that they did so based on the perceived value of physical examination. We did not ask participants their views on the relative merits or drawbacks of physical examination but only about their direct experiences performing it. Other researchers might have conducted the interviews differently and interpreted the data in different ways. A different method, such as observational research, or a questionnaire study could reveal different insights.

Having noted those limitations, we emphasize that our purpose was not to present "facts" but to gain meaningful insights, recognizing that all interpretations are tentative. Interpretive research of this type is made more rigorous by the use of preexisting theory as an interpretive tool. Our interpretation of physical examination as an embodied human interaction resonates with the work of French philosopher Maurice Merleau-Ponty, who proposed that it is impossible to separate mind and body. Physicians' experiences mirror his argument that the body is not an object but an agent in meaning making. ${ }^{29}$ Repeated performances of tasks become habits of practice. Physicians' bodies accumulate experience and become finely tuned, responsive to the moment. They can perform physical examination almost without thought because their bodies understand in a prelogical, prereflective manner. More than a routine or a cognitive process, physical examination is a creative engagement between the body of a physician and the body of a patient. The act of physical examination brings our human connection to the fore, it brings forth vulnerability, but in doing so it reveals our interrelatedness in the world.

The implications of this work are to highlight relational aspects of physical examination and encourage fellow practitioners to engage in a dialog that treats physical examination holistically rather than as only a diagnostic tool. The evidence this research contributes to that dialog is that experienced family physicians performed physical examination "even when it wasn't needed (diagnostically)" to build rapport, continuity, and trust. Physical examination facilitated nonverbal communication, mediated by touch, ${ }^{37}$ facial expression, and use of space. Participants emphasized that laying on hands demonstrated they were attentive to patients' concerns. It signaled "being there."

This work also has implications for research. A recent review of touch ${ }^{40}$ - the sense that mediates contact between physicians' and patients' bodies in the course of physical examination-found numerous articles from other professions, chiefly nursing, but only 4 qualitative studies in medicine, 2 set in UK family medicine. ${ }^{41,42}$ Touch was an important part of nonverbal communication, but it was fraught with tensions between expressing caring and risking professional sanction. Physical examination was a therapeutic intervention in itself, ${ }^{43}$ not solely a means of making diagnoses. To date, the physician's body has been largely absent ${ }^{44-46}$ from health care literature. Rather than a neutral conveyer and interpreter of physical facts, we propose the physician's body is an active agent. Further research could attend to both nonverbal communication and subtle sensory responses, which would offer new ways of understanding doctor-patient engagement. It could also address an important limitation of this study by examining the intersubjective experience of physical examination from both patients' and physicians' perspectives, perhaps based on direct observation and less subject to recall bias.

\section{CONCLUSION}

Contemporary clinical practice is in a state of flux. Family physicians experience tensions between their roles as diagnosticians, technicians, and healers. There are times when information and technological proficiency overshadow emotional engagement and rapport. While acknowledging the advantages technology offers, we should not dismiss physical examination as nostalgia. Rather, it combines the science and art of clinical practice and is an important way of knowing. It is a form of nonverbal communication within doctor-patient relationships that promotes rapport and trust. Physical examination is pathic as well as gnostic. It brings forth various dimensions of our humanity as family physicians. 
To read or post commentaries in response to this article, see it online at http://www.AnnFamMed.org/content/17/4/304.

Key words: physical examination; technology; relationship-centered care; qualitative; phenomenology; nonverbal communication; embodiment

Submitted September 21, 2018; submitted, revised, February 21, 2019; accepted March 10, 2019.

Funding support: This project was funded by the Office of Health and Medical Education Scholarship, Cumming School of Medicine, University of Calgary.

Previous presentations: Passé or a time to pause? A phenomenological study of family physicians' experiences of physical examination; British Journal of General Practice Research Conference; March 23, 2018; London, United Kingdom; and Experiencing the unexpected during physical examination, a phenomenological study; The Qualitative Report Annual Conference; January 11-13, 2018; Fort Lauderdale, Florida; and Describing the Pause: A phenomenological study of physical examination in family practice; Family Medicine Forum; November 8-11, 2017; Montreal, Quebec, Canada.

Acknowledgments: Many thanks to our participants for sharing their experiences. Thanks also to Prof Wayne Weston and Prof Joanna Bates for their helpful feedback on earlier drafts.

Supplementary materials: Available at http://www.AnnFamMed. org/content/17/4/304/suppl/DC1/.

\section{References}

1. Ahmed AM. Bedside teaching at the Cinderella status. Options for promotion. Saudi Med J. 2010;31(7):739-746.

2. Ende J, Fosnocht KM. Clinical examination: still a tool for our times? Trans Am Clin Climatol Assoc. 2002;113:137-150.

3. Feddock CA. The lost art of clinical skills. Am J Med. 2007;120(4): 374-378.

4. Jauhar S. The demise of the physical exam. N Engl J Med. 2006; 354(6):548-551.

5. Wu EH, Fagan MJ, Reinert SE, Diaz JA. Self-confidence in and perceived utility of the physical examination: a comparison of medical students, residents, and faculty internists. J Gen Intern Med. 2007; 22(12):1725-1730.

6. Haring CM, Cools BM, van der Meer JW, Postma CT. Student performance of the general physical examination in internal medicine: an observational study. BMC Med Educ. 2014;14(1):73.

7. Sharma S. A single-blinded, direct observational study of PGY-1 interns and PGY-2 residents in evaluating their history-taking and physical-examination skills. Perm J. 2011;15(4):23-29.

8. Verghese A, Charlton B, Kassirer JP, Ramsey M, loannidis JP. Inadequacies of physical examination as a cause of medical errors and adverse events: a collection of vignettes. Am J Med. 2015;128(12): 1322-1324, e1323.

9. Asif T, Mohiuddin A, Hasan B, Pauly RR. Importance of thorough physical examination: a lost art. Cureus. 2017;9(5):e1212.

10. De Freitas S, Connolly C, Sharif F. Back to the bedside: cutting costs with physical examination skills. Clin Anat. 2017;30(4):431-431.

11. Elder A, Japp A, Verghese A. How valuable is physical examination of the cardiovascular system? BMJ. 2016;354:i3309.
12. Störmann S, Stankiewicz M, Raes $P$, et al. How well do final year undergraduate medical students master practical clinical skills? GMS J Med Educ. 2016;33(4):Doc58.

13. Mookherjee S, Hunt S, Chou CL. Twelve tips for teaching evidencebased physical examination. Med Teach. 2015;37(6):543-550.

14. Verghese A, Brady E, Kapur CC, Horwitz RI. The bedside evaluation: ritual and reason. Ann Intern Med. 2011;155(8):550-553.

15. Hunt DP. Do patients with advanced cancer value the physical examination? Cancer. 2014;120(14):2077-2079.

16. Carel H. Illness: The Cry of the Flesh. London, UK: Routledge; 2016.

17. Frank A. The Wounded Storyteller: Body, Illness and Ethics. Chicago, IL: University of Chicago Press; 1997.

18. Klitzman R. When Doctors Become Patients. Oxford, UK: Oxford University Press; 2008.

19. Kravetz RE. To touch or not to touch: that is the question. Am J Gastroenterol. 2009;104(9):2143-2144.

20. Verghese A. A touch of sense. Health Aff (Millwood). 2009;28(4): 1177-1182.

21. Moules NJ, McCaffrey G, Field J, Laing C. Conducting Hermeneutic Research: From Philosophy to Practice. New York, NY: Peter Lang Publishing; 2015.

22. Van Manen M. Phenomenology of Practice: Meaning-Giving Methods in Phenomenological Research and Writing. Walnut Creek, CA: Left Coast Press; 2014.

23. King N, Carroll C, Newton P, Dornan T. "You can't cure it so you have to endure it": the experience of adaptation to diabetic renal disease. Qual Health Res. 2002;12(3):329-346.

24. King N, Cassell C, Symon G. Using Templates in the Thematic Analysis of Texts. London, UK: Sage Publications; 2004.

25. McLachlan E, King N, Wenger E, Dornan T. Phenomenological analysis of patient experiences of medical student teaching encounters. Med Educ. 2012;46(10):963-973.

26. Coffey A, Atkinson P. Making Sense of Qualitative Data: Complementary Research Strategies. Thousand Oaks, CA: Sage Publications; 1996.

27. Buytendijk F. Some aspects of touch. J Phenomenological Psychol. 1970;1(1):99-122.

28. Derrida J. On Touching-Jean-Luc Nancy. Stanford, CA: Stanford University Press; 2005.

29. Merleau-Ponty M. Phenomenology of Perception. London, UK: Routledge \& Kegan Paul; 1962/1945.

30. Merleau-Ponty M. The Primacy of Perception, and Other Essays on Phenomenological Psychology, the Philosophy of Art, History and Politics: Edited, With an Introduction by James M. Edie. Evanston, IL: Northwestern University Press; 1964.

31. Merleau-Ponty M. The Visible and the Invisible: Followed by Working Notes. Evanston, IL: Northwestern University Press; 1968.

32. Sartre J-P. Being and Nothingness. New York, NY: Washington Square Press; 1992.

33. Stein E. On the Problem of Empathy. New York, NY: Springer; 2013.

34. Finlay L. "Reflexive embodied empathy": a phenomenology of participant-researcher intersubjectivity. J Humanist Psychol. 2005; 33(4):271-292.

35. van Manen M. Technics of touch in the neonatal intensive care. Med Hum. 2012:38:91-96.

36. van Manen $M$. The pathic nature of inquiry and nursing. In: Nursing and the Experience of Illness: Phenomenology in Practice. London, UK: Routledge; 1999:17-35.

37. Kneebone R. Getting back in touch. Lancet. 2018;391(10128):1348. 
38. Kadakia KC, Hui D, Chisholm GB, Frisbee-Hume SE, Williams JL, Bruera E. Cancer patients' perceptions regarding the value of the physical examination: a survey study. Cancer. 2014;120(14): 2215-2221.

39. Kravitz RL, Callahan EJ. Patients' perceptions of omitted examinations and tests: a qualitative analysis. J Gen Intern Med. 2000;15(1): 38-45.

40. Kelly MA, Nixon L, McClurg C, Scherpbier A, King N, Dornan T. Experience of touch in health care: a meta-ethnography across the health care professions. Qual Health Res. 2018;28(2):200-212.

41. Cocksedge S, George B, Renwick S, Chew-Graham CA. Touch in primary care consultations: qualitative investigation of doctors' and patients' perceptions. Br J Gen Pract. 2013;63(609):e283-e290.
42. Cocksedge S, May C. Doctors' perceptions of personal boundaries to primary care interactions: a qualitative investigation. Commun Med. 2009;6(2):109-116.

43. Novack DH, Epstein RM, Paulsen RH. Toward creating physicianhealers: fostering medical students' self-awareness, personal growth, and well-being. Acad Med. 1999;74(5):516-520.

44. Harris A. In a moment of mismatch: overseas doctors' adjustments in new hospital environments. Sociol Health IIIn. 2011;33(2):308-320.

45. Lupton D, Maslen S. Telemedicine and the senses: a review. Sociol Health IIIn. 2017;39(8):1557-1571.

46. Maslen S. Sensory work of diagnosis: a crisis of legitimacy. Senses Society. 2016;11(2):158-176.

\section{CHANGE-OF-ADDRESS FORM FAMMILY MEDICINE}

Please complete this form and mail to the following address or fax to Annals Circulation at 913-906-6080:

Annals of Family Medicine, Circulation Department, 11400 Tomahawk Creek Pkwy, Leawood, KS 66211-2680

Check if member of sponsoring organization:

$$
\begin{array}{lc}
\square \text { AAFP } & \square \text { ABFM } \square \text { STFM } \square \text { ADFM } \\
\square \text { AFMRD } & \square \text { NAPCRG } \square \text { CFPC }
\end{array}
$$

ID number from label on your journal cover

OLD Information (Please print.)

\begin{tabular}{ll}
\hline Name \\
\hline Company (if applicable) \\
\hline Address (Street plus Apt or Ste) \\
\hline City & Postal Code (9-digit ZIP for US) \\
\hline Country & Fax \\
\hline Telephone & \\
\hline E-Mail &
\end{tabular}

NEW Information (Please print.)

\begin{tabular}{lc}
\hline Name \\
\hline Company (if applicable) \\
\hline Address (Street plus Apt or Ste) \\
\hline City & \\
\hline Country & Postal Code (9-digit ZIP for US) \\
\hline Telephone & Fax \\
\hline E-Mail &
\end{tabular}

